\title{
Dental School and Community Clinic Financial Arrangements
}

\author{
Wilhelm Piskorowski, D.D.S.; Howard L. Bailit, D.M.D., Ph.D.; \\ Taegen L. McGowan, M.P.H.; Rachel E. Krell, B.A.
}

Abstract: In community-based dental education programs, student-provided services can be an important source of community clinic and practice revenues. The University of Michigan School of Dentistry has developed a revenue-sharing arrangement with multiple community clinics and practices. During their ten-week externship, senior students produce at least $\$ 800$ a day in patient care revenues, and the school receives an average of $\$ 165$ per student per day from community sites. These funds are used to cover program costs and enrich the curriculum. Revenue-sharing with community clinics and practices helps to ensure program longevity and is an increasingly significant source of school revenues.

Dr. Piskorowski is Assistant Clinical Professor and Director of Community Outreach, Department of Cariology, Restorative Sciences, and Endodonics, School of Dentistry, University of Michigan; Dr. Bailit is Professor Emeritus, Department of Community Medicine, School of Medicine, University of Connecticut Health Center; Ms. McGowan is Research Assistant, Department of Community Medicine, School of Medicine, University of Connecticut Health Center; and Ms. Krell is Research Assistant, Department of Community Outreach, School of Dentistry, University of Michigan. Direct correspondence and requests for reprints to Dr. Wilhelm Piskorowski, University of Michigan, School of Dentistry, Department of Cariology, Restorative Sciences, and Endodonics, 1101 N. University Avenue, Ann Arbor, MI 48109; 734-764-6338 phone; 734-936-1597 fax; wapdds@umich.edu.

Keywords: community-based dental education, community dental clinics, dental school finances, revenue-sharing

$\mathrm{C}$ ommunity-based dental education programs can be mutually beneficial to dental schools and community clinics. Evidence suggests that students gain important knowledge, skills, and self-confidence from working in these real delivery systems, where they interact with dentists and other clinical and administrative staff. ${ }^{1-6}$ For community clinics, students increase their capacity to provide care to underserved patients and appear to energize clinic dentists and staff with their enthusiasm and questions. Also, a percentage of students seek employment in safety-net clinics because of their positive experience in these settings. ${ }^{7}$

There is also a financial component to this relationship. Other articles in this report consider the impact of community-based dental education on school and clinic finances and on community clinic finances, and both report positive results. ${ }^{8,9}$ That is, under the right circumstances both dental schools and clinics generate more net revenues from communitybased education programs.

One challenge for community-based education programs is reliance on increasingly constrained school funds to cover their operational costs. To address this problem, the University of Michigan School of Dentistry negotiated a revenue-sharing agreement with its community clinic partners. The purpose of this chapter is to describe the strategy used by the school to change its financial relationships with safety-net dental clinics and private practices. The specific objectives are to describe the evolution of community service-learning programs at the University of Michigan School of Dentistry; discuss the process of negotiating with community partners for a fixed daily payment per student; examine data on the financial impact of dental students in community settings; and review the use of these funds to advance the school's education and service programs.

\section{Results}

For nearly eighty years, the University of Michigan School of Dentistry has been engaged in community outreach programs. Starting in the 1930s, senior dental students travelled to county health departments for one-week "field trips" to gain a better understanding of local oral health conditions. In the 1970s, selected students spent six weeks in Traverse City providing care to migrant workers and in Flint treating patients with special needs. Typically, these were summer-only experiences. 
In 2000, community experiences became an integral part of the school's clinical education program. Approximately, \$2 million was raised from external sources to support this initiative, including a special grant from the state Medicaid program. In the beginning, all dental students were required to spend three weeks in community clinics providing care to low-income patients. Dental hygiene students and general dentistry residents also participated in this program. By 2002, the program had expanded to four weeks, and in 2011 senior students will spend ten weeks in community externships.
Figure 1 presents the location of partner clinics and practices. Distributed throughout the state, they include federally qualified health centers (FQHCs), Indian Health Service (IHS) clinics, other community clinics, private group practices, correctional facilities, and donated service clinics. Students also travel to seven developing countries.

An important factor in the program's success was the use of digital technology. Students had Internet access to curricular material (e.g., text, lectures, photos, slides) and were able to keep up with courses. They could also remotely access and manage their

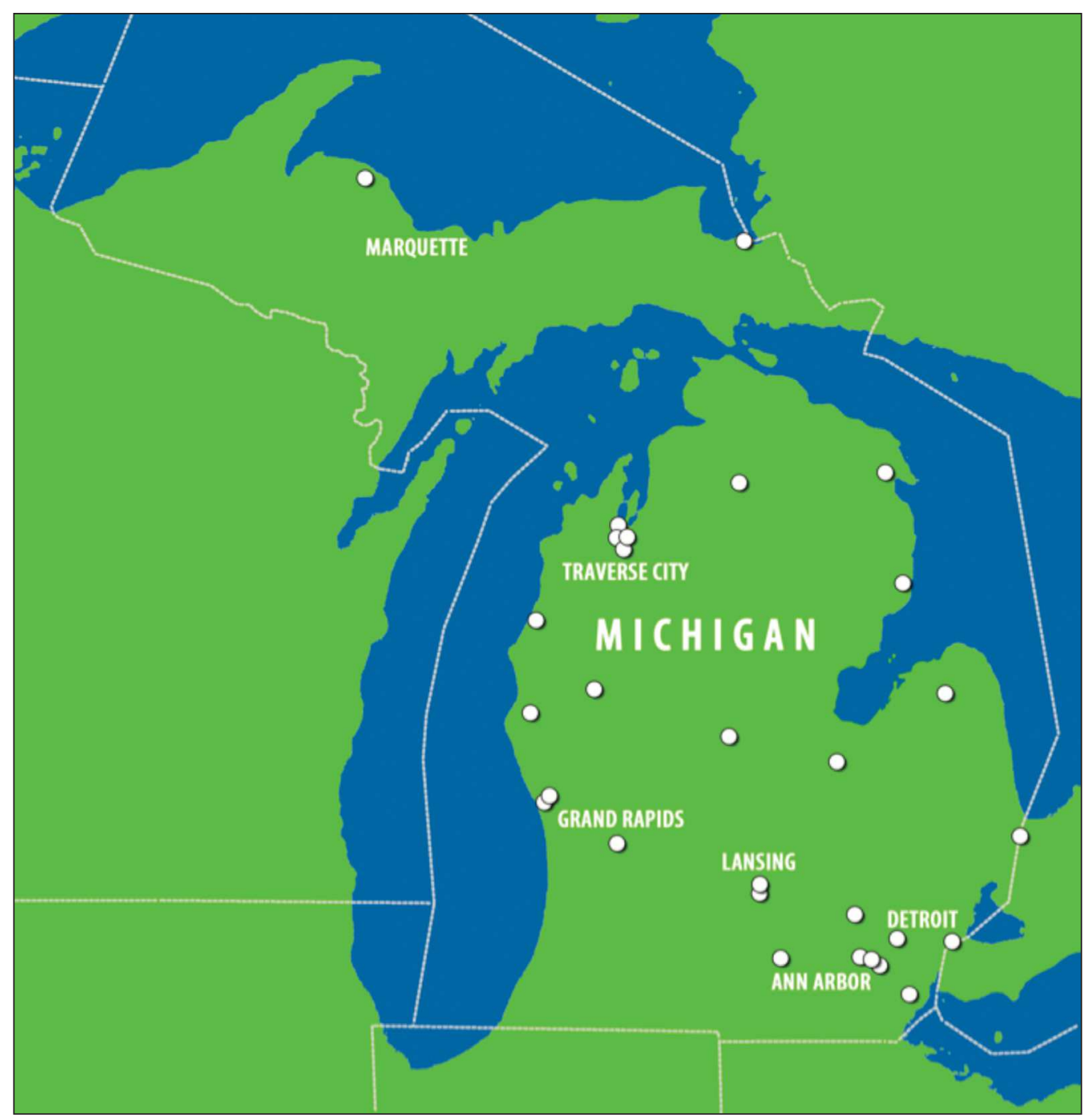

Figure 1. University of Michigan School of Dentistry community clinic locations 
school patient population. Tablet computers were used to collect productivity and assessment information from students and preceptors, respectively.

The program has broad support among the faculty, administrators, and students. In addition, it has changed the career plans of some students. Over 20 percent of the 2009 graduating class reported that, once in practice, they expected a large percentage of their patients to be underserved.

\section{Financial Contracts}

Initially, there was no direct financial exchange between the school and community clinics and practices. That is, the school did not pay clinics to take students, and clinics did not share student-generated surplus revenues. Some clinics did pay for student living expenses if they were beyond commuting distance.

Based on the program director's experience in private practice, student clinic productivity, and community clinic funding mechanisms (per visit), it was apparent that students were generating surplus revenues for community clinics. Also, FQHCs received $\$ 25,000$ per full-time equivalent (FTE) student per year from the Michigan Department of Community Health to offset the cost of accommodating students. For all these reasons, the decision was made to ask partnering clinics and practices to share studentgenerated patient care revenues.

The question was: how much to ask for? Since fourth-year students averaged $\$ 165$ per clinic session at the school, a universal revenue-sharing agreement was developed with all partner sites that approaches this amount. Presently, all contracts are for five years and have a single rate, greatly reducing the time spent negotiating contracts. The exceptions to this general agreement are in the payment method and for clinics that do not charge patients and have no external subsidy. Clinics meeting these criteria do not share student revenues with the school.

\section{Clinic Negotiations}

When revenue-sharing started, all participating sites were FQHCs. They not only kept the revenues generated by students, but they received approximately $\$ 25,000$ from the state Medicaid program for each FTE student. During the first period of negotiations, these additional Medicaid funds were helpful in convincing clinics to adopt the new revenue-sharing agreement. Some clinics negotiated different methods of payment (e.g., per year), but all were based on the $\$ 165$ per day. Importantly, no clinic ended its relationship with the school because of the revenue-sharing agreement. Now, safety-net clinics are generally aware of the school's revenue-sharing policy, and all new sites have accepted the required payment schedule.

After several years of experience, we believe there are three essential factors in negotiating revenue-sharing with clinics and practices. First, the negotiator should always be the program director, and he or she should have a dental degree, several years of clinical practice and faculty teaching experience, and knowledge of clinic payer payment methods. Second, student-generated clinic data should be organized and presented to best engage key clinic staff. For example, the chief financial officer, who is usually an accountant, should be shown the student financial data. The chief executive officer and dental director are often clinically focused and want to see data on the program's impact on clinic productivity, staff morale, and recruitment of dentists. Third, clinics are very interested in the experiences of other participating clinics, and a few select ones should be used as references. When prospective clinics hear the value of the program from program clinics, they become more comfortable in participating.

\section{Financial Impact on Community Clinics}

Table 1 summarizes 2009-10 student-generated revenues in three types of clinical settings. This includes the average daily per student revenues, average number of student days per year, and average gross student production per clinic/practice per year for sites where data were available. Each student produced more than $\$ 800$ per day-a significant amount of revenue in all three settings. An FQHC clinic with 364 days of student service earned an average of $\$ 293,253$; community clinics with fortytwo student days earned an average of $\$ 38,350$; and the private practice group with 78.5 student days earned $\$ 68,515$.

No information was available on the marginal expenses that clinics had to pay for students. Since all students had a full-time dental assistant, and dental assistants probably earned $\$ 35,000$ per year with fringe benefits, the average cost of dental assistants was around $\$ 130$ per day. The other marginal studentrelated expense was supplies, which were probably 
less than $\$ 25$ per day. Based on these admittedly rough calculations, students in the average clinic were generating a surplus of at least $\$ 645$ per day.

\section{Financial Impact on Dental School}

Table 2 presents actual and projected school revenues from community clinics and practices where data were available for 2007-10 and 2012, respectively. Based on an average of $\$ 165$ per student per day, the amount of revenue is proportional to the number of student weeks and participating clinics. For example, in 2008 the students spent five weeks in FQHC clinics, and the school received $\$ 307,152$. In 2010 , students spent eight weeks in the community, and the school received $\$ 546,242$. In 2012, revenues are projected to approach $\$ 800,000$. The percentage of revenues shared with the school ranged from 17 to 24 percent of the student-generated revenues.

However, the financial impact of the outreach program goes beyond revenue-sharing. Figure 2 shows that as the amount of time senior students spent in community clinics increased, so did dental school clinic revenues. In contrast to expectations, student revenues increased about $\$ 100,000$ from 2007 to 2009 when students spent an additional four weeks in the community. This comparison controls for changes in clinic fees and number of students. Presumably, and as reported by other investigators, community experiences increased student skills, knowledge, and self-confidence, and this resulted in significantly greater productivity in the school clinics. ${ }^{1-6}$

Another source of community program-associated revenues comes from additional student tuition. As school clinic space became available with more weeks in the community, the school increased student enrollment by adding an international program.

\section{Use of Funds}

The school uses the majority of the funds generated by revenue-sharing to cover program costs such as student transportation, gas, and lodging. For example, last year the school leased sixteen vehicles for student travel to community sites, booked over 800 weeks of hotel lodging, and assisted with travel costs to international sites where students participated in multidisciplinary university projects. Funds are also used to support educational and research pilot projects and to enrich the curriculum. In addition, the program tries to give back to preceptor dentists and covers the cost of several continuing education seminars. Any unused revenues go to the school's general operating fund.

As financial support for dental education declines in Michigan (and in most other states), the additional direct and indirect funds from the community-based program are a significant factor

Table 1. Average daily student production per clinic, students' days of outreach, and gross student production by clinic type, 2009-10

\begin{tabular}{lccc} 
Clinic Type & $\begin{array}{c}\text { Daily Student } \\
\text { Production Per Clinic }\end{array}$ & $\begin{array}{c}\text { Days of Student } \\
\text { Outreach }\end{array}$ & $\begin{array}{c}\text { Gross Student } \\
\text { Production Per Clinic }\end{array}$ \\
\hline FQHC 2009 (4) & $\$ 806$ & 364 & $\$ 293,253$ \\
Community 2010 (5) & $\$ 906$ & 42 & $\$ 38,350$ \\
Private practice 2009 (1) & $\$ 870$ & 78.5 & $\$ 68,515$
\end{tabular}

Note: Numbers in parentheses under Clinic Type represent number of clinics in data set.

Table 2. Annual shared student-generated revenues by community weeks and clinical setting

\begin{tabular}{|c|c|c|c|c|c|}
\hline & 2007 & 2008 & 2009 & 2010 & 2012 Projection \\
\hline Weeks & 4 & 5 & 8 & 8 & 10 \\
\hline FQHC clinics & $\$ 209,696$ & $\$ 307,152$ & $\$ 434,146$ & $\$ 437,033$ & $\$ 552,980$ \\
\hline Community clinics & - & - & - & $\$ 28,952$ & $\$ 127,320$ \\
\hline Indian Health Service clinics & - & - & $\$ 16,252$ & $\$ 67,553$ & $\$ 69,580$ \\
\hline Private practice & - & - & $\$ 5,330^{\dagger}$ & $\$ 12,704$ & $\$ 14,190$ \\
\hline
\end{tabular}




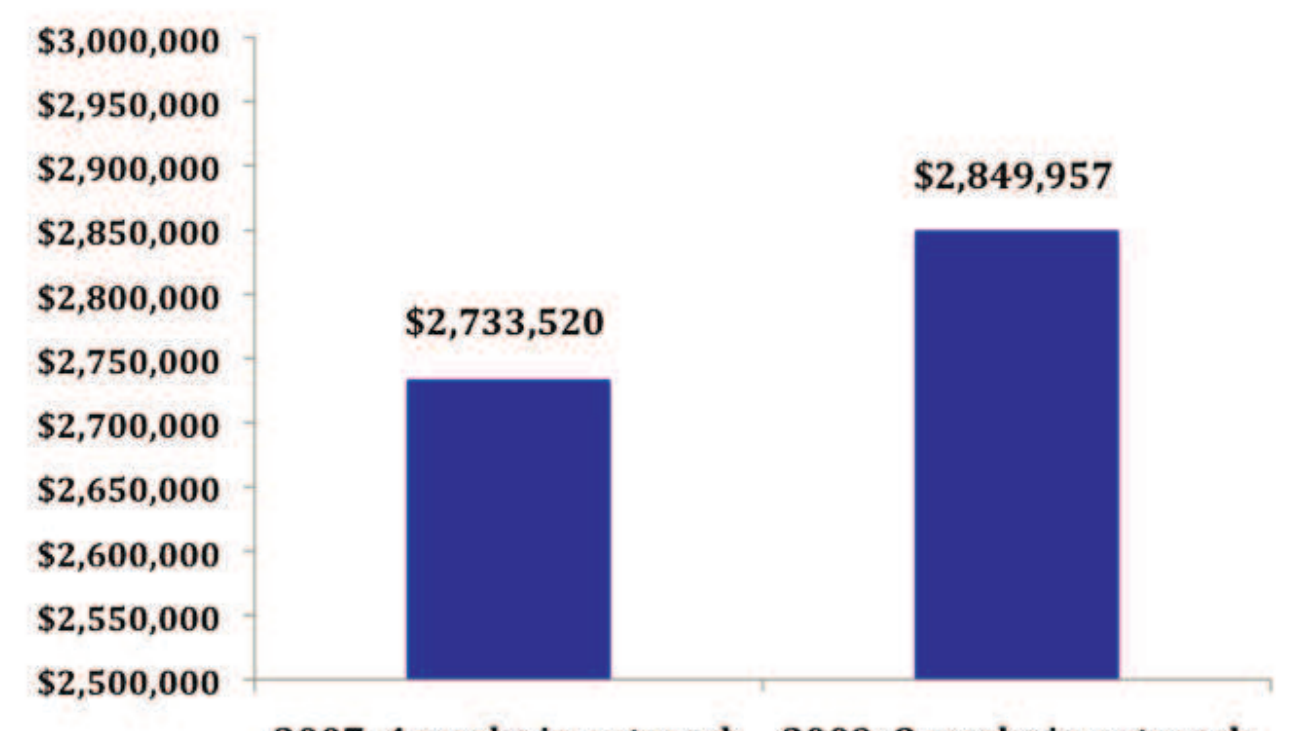

2007: 4 weeks in outreach 2009: 8 weeks in outreach

Figure 2. Relationship between weeks in community-based dental education and senior student-generated dental school revenues

in maintaining the quality of educational and service programs. Equally important, there is broad faculty support for the program, in part, because of the positive contribution it makes to the school's finances and the enthusiasm generated by the students.

\section{Conclusion}

The University of Michigan School of Dentistry has developed a successful revenue-sharing program with community clinics and practices. In large part, this is because students make a valuable contribution to increasing their capacity to treat more underserved patients, to recruit dental staff, and to produce surplus revenues. Interestingly, all clinics and practices approach the same $\$ 165$ per student per day, even though they have a very different mix of payers and payment methods. This suggests that students are producing adequate revenues in many different types of clinical environments.

Operationally, successful negotiations require having strong relationships with community clinics, a program director who understands community clinic payment methods, and data on student productivity. Now that the revenue-sharing policy is established and widely known, it is no longer a major issue in partnering with new clinics.

The contribution of the community-based program to the school's finances is significant and growing, as the time seniors spend in the community increases and other sources of school revenues decline. Further, there are important related revenues that come from the community program. These include increased school clinic revenues from more productive students and more tuition dollars from the enrollment of additional students. These funds are used to support the program and enrich the curriculum of all students.

Finally, while community programs have a positive impact on school finances, their most important contribution is improving the quality of dental education. It is important to keep the primary mission of the school central to these programs.

\section{Acknowledgments}

The authors thank Tom Veryser, D.D.S., M.H.S.A., CEO of Michigan Community Dental Clinics, and Jed Jacobson, D.D.S., M.S., M.P.H., Chief Science Officer of Renaissance Health Service Corporation, for pioneering the University of 
Michigan community program and their continued contribution to its development. We also thank Steven Stefanac, D.D.S., M.S., Associate Dean for Patient Services, University of Michigan School of Dentistry, and Mark Fitzgerald, D.D.S., M.S., Associate Professor and Chair, University of Michigan School of Dentistry, for their guidance and support in the growth of the community program.

\section{REFERENCES}

1. Mascarenhas AK, Henshaw M. Infrastructure for a community-based dental education program: students and clinics. J Dent Educ 2010;74(10 Suppl):S17-S24.

2. Strauss RP, Stein MB, Edwards J, Nies KC. The impact of community-based dental education on students. J Dent Educ 2010;74(10 Suppl):S42-S55.

3. Mascarenhas AK, Freilich SR, Henshaw MM, Jones JA, Mann ML, Frankl SN. Evaluating externship programs: impact of program length on clinical productivity. J Dent Educ 2007;71(4):516-23.
4. Atchison KA, Hewlett ER, Friedman JA. The pipeline program at the University of Illinois at Chicago College of Dentistry. J Dent Educ 2009;73(2 Suppl):S120-S134.

5. Friedman JA, Thind A, Davidson PL. The pipeline program at Meharry Medical College School of Dentistry. J Dent Educ 2009;73(2 Supp1):S83-S95.

6. Perry M. The experiences of community dental clinic directors with dental students and dental school collaborations. J Dent Educ 2010;74(10 Suppl):S56-S61.

7. Piskorowski WA, Fitzgerald M, Mastey J, Krell RE. Development of a sustainable community-based dental education program. J Dent Educ 2011;75(8):1038-43.

8. Mashabi S, Mascarenhas AK. Impact of community externships on the clinical performance of senior dental students. J Dent Educ 2011;75(10 Suppl):S36-S41.

9. Le H, McGowan TL, Bailit HL. Community-based dental education and community clinic finances. J Dent Educ 2011;75(10 Suppl):S48-S53. 